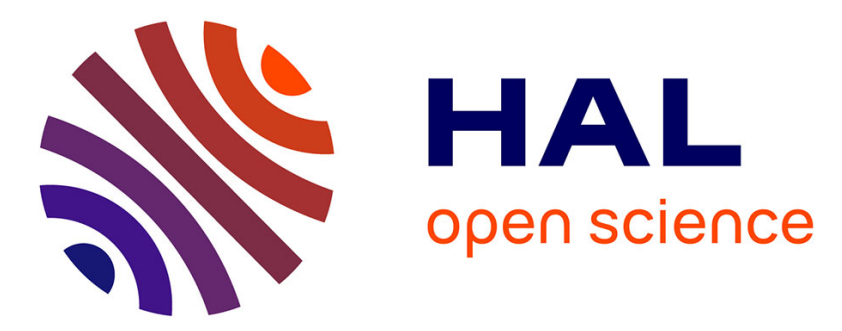

\title{
Thermoelastic investigation of a quartz tuning fork used in infrared spectroscopy
}

Michel Spajer, Bruno Cavallier, Sébastien Euphrasie, Gaël Matten, Xavier Vacheret, Pascal Vairac, David Vernier, Alain Jalocha

\section{- To cite this version:}

Michel Spajer, Bruno Cavallier, Sébastien Euphrasie, Gaël Matten, Xavier Vacheret, et al.. Thermoelastic investigation of a quartz tuning fork used in infrared spectroscopy. Applied Physics Letters, 2013, 103, pp.201111. 10.1063/1.4830417 . hal-00908609

\section{HAL Id: hal-00908609 \\ https://hal.science/hal-00908609}

Submitted on 25 Nov 2013

HAL is a multi-disciplinary open access archive for the deposit and dissemination of scientific research documents, whether they are published or not. The documents may come from teaching and research institutions in France or abroad, or from public or private research centers.
L'archive ouverte pluridisciplinaire HAL, est destinée au dépôt et à la diffusion de documents scientifiques de niveau recherche, publiés ou non, émanant des établissements d'enseignement et de recherche français ou étrangers, des laboratoires publics ou privés. 


\title{
Thermoelastic investigation of a quartz tuning fork used in infrared spectroscopy
}

\author{
Michel Spajer ${ }^{1, a)}$, Bruno Cavallier ${ }^{1}$, Sébastien Euphrasie ${ }^{1}$, Gaël Matten $^{1}$, \\ Xavier Vacheret ${ }^{1}$, Pascal Vairac ${ }^{1}$, David Vernier ${ }^{1}$ and Alain Jalocha ${ }^{2}$ \\ ${ }^{1}$ Institut FEMTO-ST, Université de Franche-Comté, CNRS, ENSMM, UTBM, \\ 32 avenue de l'Observatoire, F-25044 Besançon cedex, France. \\ ${ }^{2}$ CILAS, Département de Photonique, 8 avenue Buffon, BP 6319, F-45000 Orléans, France.
}

(Received 23 September 2013; accepted 20 October 2013, published online 13 November 2013)

\begin{abstract}
The performances of quartz tuning forks (QTF) used in infrared spectroscopy for pollutant detection are investigated. The transduction between light and QTF vibration is elucidated thanks to QTF encapsulation under vacuum. From the sensitivity enhancement which is obtained we conclude that their interaction is photo-thermoelastic rather than photo-thermoacoustic. A mapping of the local sensitivity of the QTF is obtained by scanning its faces with the excitation probe beam. The comparison between the signal mapping and the theoretical strain mapping indicates that the most efficient areas of the QTF correspond to the areas where the strain or stress are the highest.
\end{abstract}

Quartz tuning forks (QTF) have proved to be efficient sensors in several domains such as Atomic Force Microscopy, ${ }^{1-3}$ magnetometry, ${ }^{4}$ and mainly shear force detection associated to Scanning Near-Field Optical Microscopy (SNOM). ${ }^{5,6}$ The ultimate noise limited sensitivity has been extensively studied in the framework of the latter application. ${ }^{5,6}$ QTF have also been successfully used in photo-acoustical spectroscopy (PAS), mainly for gas identification ${ }^{7}$ in far infrared domain but the same detection scheme has been transposed to absorption spectroscopy of solid materials (thin layer, powder, ...). ${ }^{8}$ In this configuration an image of the sample is focused on the QTF which acts as a mechanical detector of the optical intensity. Its main advantage is its sensitivity over a large span of the optical spectrum, mainly in infra-red domain. Spectroscopic analysis requires a tunable source, the light of which is reflected by the absorbing layer or powder under study. The source spectrum is modified by the absorption spectrum of the layer. In the same way as for PAS, the source intensity is modulated at the tuning fork resonance frequency to optimize the signalto-noise ratio.

Van Neste et $a l .{ }^{8}$ assume that the tuning fork is excited by acoustic waves which are created at the air/surface interface by the local periodic heating of the fork electrode and generate a piston effect on the prong. The purpose of this study is to elucidate the physical origin of the signal and to characterize precisely the spatial variations of the fork sensitivity.

The bench is depicted in Figure 1. For the need of sensor characterization we used a continuous laser diode emitting in the visible domain ( $4 \mathrm{~mW}$ at $\lambda=670 \mathrm{~nm}$ ) whose current is modulated at the resonance frequency of the tuning fork. The piezoelectric current delivered by the QTF (dimension $\sim 6$ $\mathrm{mm} \times 1.5 \mathrm{~mm} \times 0.3 \mathrm{~mm}$ ) feeds a lock-in amplifier after a trans-impedance amplifier which plays an important role in the signal-to-noise ratio. Different amplifiers have been tested, the signal being calibrated in terms of mechanical vibration amplitude and optical excitation with the help of an interferometric heterodyne probe, ${ }^{9}$ where both excitation and measurement spots are conventionally located at $2 / 3$ of the prong length. The best performances we obtained in this configuration were a sensitivity of $4.19 \mathrm{~V} / \mathrm{W}$, a noise level of $0.40 \mu \mathrm{V} / \mathrm{Hz}^{1 / 2}$ and a noise equivalent power (NEP) of 0.10 $\mu \mathrm{W} / \mathrm{Hz}^{1 / 2}$.

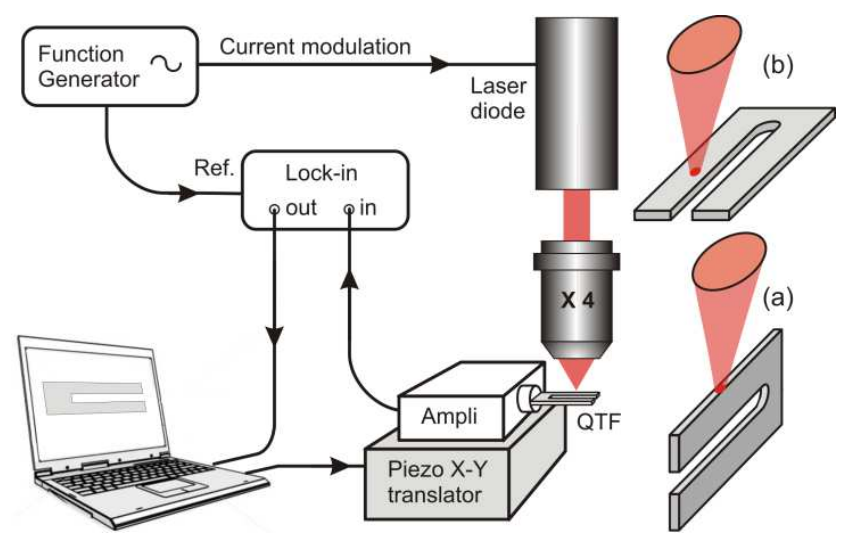

FIG. 1. Characterization bench. The QTF can be irradiated sidewards (a) or frontwards (b).

Barnes et al. ${ }^{10}$ obtained a lower NEP with a microcantilever under off-resonance excitation but its micrometric dimension must be taken into account. It is a real drawback for a handy measurement device due to alignment problems and a weak efficiency when the surface of interest is imaged on the sensor.

During this calibration process the tuning fork was excited sidewards but it can be excited frontwards as well, as represented on Figure 1. It is mounted on a XYZ piezo translator which is driven by a computer. With a sideward irradiation the signal is maximum when the position of the spot is near the basis of the prong. Figure 2 puts into evidence this dependence despite the noisy features of the signal when

a) Author to whom correspondence should be sent. Electronic mail: michel.spajer@univ-fcomte.fr . 
the beam is focused on the surface of the electrode. This noise comes from the granularity of the metal layer which generates a speckle effect in the reflected beam and to a corresponding modulation of the absorption. A smoothed curve is obtained if the exciting beam is slightly defocused.

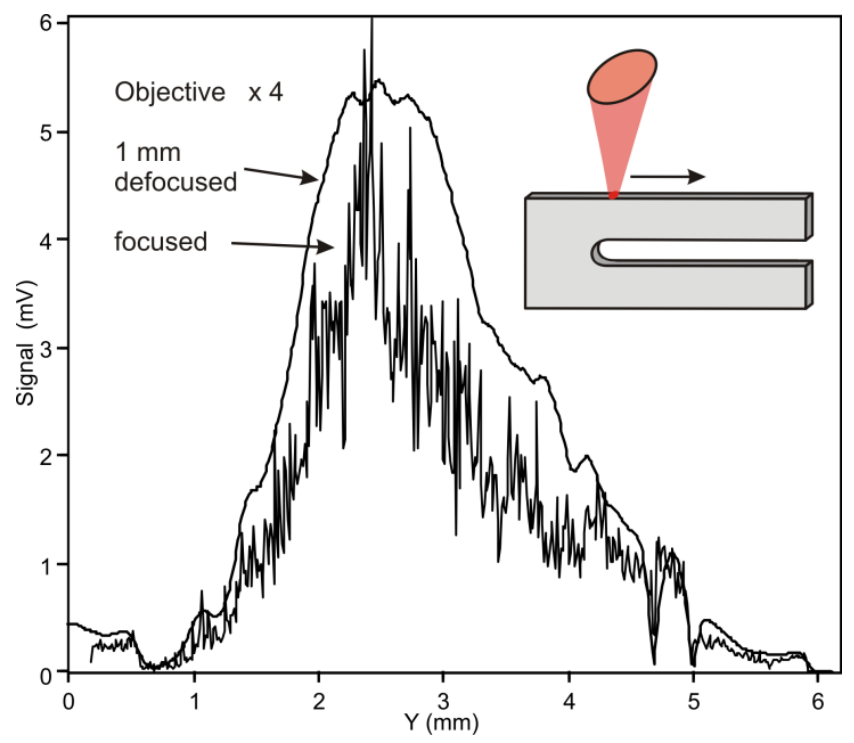

FIG. 2. Piezoelectric signal of the QTF vs. position of the spot on the QTF side.

Two observations convinced us that the transduction mechanism is due to photo-thermoelastic phenomena inside the QTF rather than photo-thermoacoustic ones in its vicinity, the effect of ambient atmosphere simply being the usual resonance damping:

1) Vacuum encapsulation of the fork yields a tenfold enhancement of the signal and restores the original $Q$ factor of the resonance in vacuum. Since acoustic waves cannot exist in vacuum, the signal cannot come from acoustic phenomena. Figure 3 compares the two resonances obtained in air and in vacuum. A difference of about one decade is visible both on $\mathrm{Q}$ and on the maximum of the signal. This demonstration was done in the visible domain with a glass window. Adaptation of the encapsulated device to the infra red domain $(\lambda=10 \mu \mathrm{m})$ would require a $\mathrm{ZnSe}$ window.

2) The signal is of the same order when the fork is turned face to the laser beam and higher when the spot is near the basis of the prong. Since the basis of the prong is the area of maximum strain and stress, the optimal position of the light impact seems related to these maxima in the excited vibration mode.

To verify this point we measure the piezoelectric response during a complete XY-scan of the laser spot on the QTF, then we compare it to the strain mapping. The signal mapping (Figure 4b) perfectly reproduces the electrode patterns of both faces (Figure 4a), because only the metal layer has a sufficient absorption to ensure a thermal transduction. The contrast due to the metallic electrodes will likely be much lower in the infrared range of a $\mathrm{CO} 2$ laser because the quartz itself is highly absorbing in this wavelength domain. The other main feature is the black line (null signal) which, according to our hypothesis, should follow the line of minimum strain. We added an image with non-linear color scale, in order to improve the visualization of the dark zone (figure 4c).

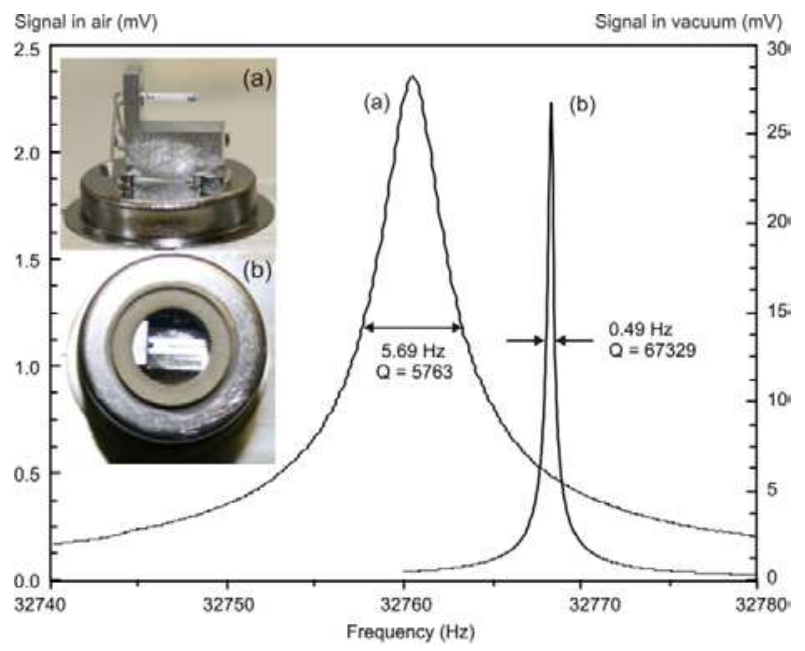

FIG. 3. Response of the QTF in air (a) and in vacuum (b).

In order to understand the overall response of the device and the physical phenomena involved, we performed numerical simulations of the experiment. The correct modeling should take into account the full coupling of elastic, thermal and electrical fields and yields to thermopiezoelectric interactions. ${ }^{11-13}$ Moreover a fluid structure model should give an even more precise model for a better understanding of the air damping. We implemented the numerical modeling on FreeFem ++ software $^{14}$ that enables us to write our own finite element variational integral forms step by step. FreeFem ++ is a high level integrated development environment for numerically solving partial differential equations. It is based on the finite element method and describes problems by their variational formulations. We use the software $G m s h^{15}$ for the 3D geometry modeling of the device, generation of the mesh data and post-processing.

In a first step we neglect the piezoelectric and thermal properties and take only into account the mechanical properties of the QTF. This simplified model allows identifying vibration modes, mapping of the elastic displacements and of the related stresses.

Elastic motion in solid is described by Hooke's law

$$
T_{i j}=C_{i j k l} \frac{\partial u_{k}}{\partial x_{l}}
$$

and by Newton's second law

$$
T_{i j, j}+\rho \omega^{2} u_{i}=0
$$




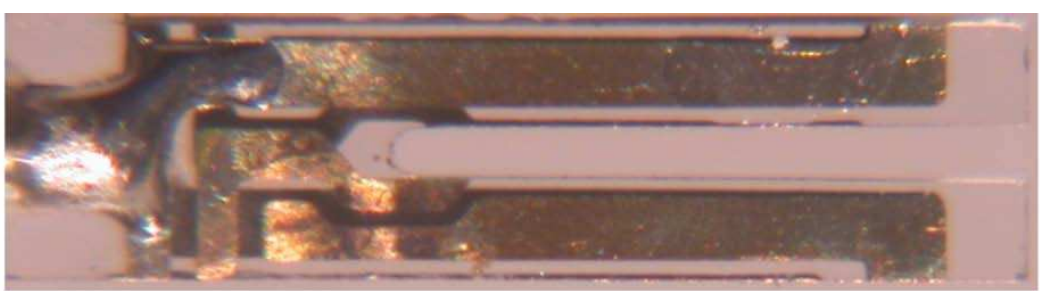

(a)

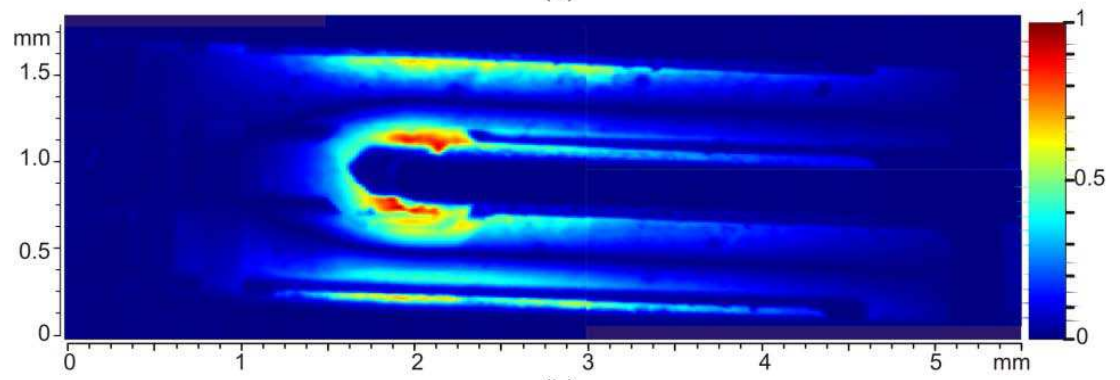

(b)

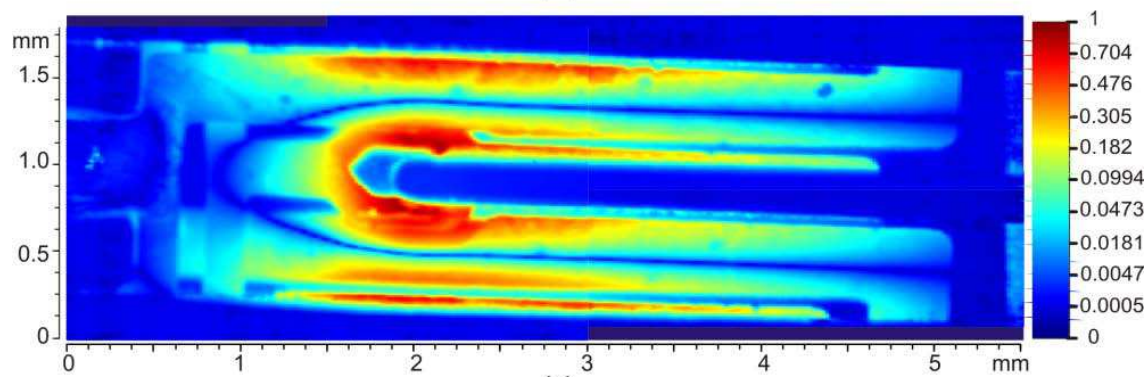

(c)

where $\boldsymbol{T}$ is the elastic stress tensor of rank $2, \boldsymbol{C}$ is the rigidity tensor of rank $4, \boldsymbol{u}$ is the displacement field, $\boldsymbol{\rho}$ is the mass density of the solid and $\boldsymbol{\omega}$ is the angular frequency. A variational formulation of the elastic problem is obtained from the above equations and related boundary conditions. With the use of the finite element method, it leads to an eigenvalue problem of the form

$$
K u=\omega^{2} M u
$$

where $\boldsymbol{K}$ is the stiffness matrix, $\boldsymbol{u}$ is the displacement vector and $\boldsymbol{M}$ is the mass matrix. Solving the eigenvalue problem of Eq.(3) gives the elastic modes and then eigenvectors $\boldsymbol{u}$ further give the modal shape of each solution.

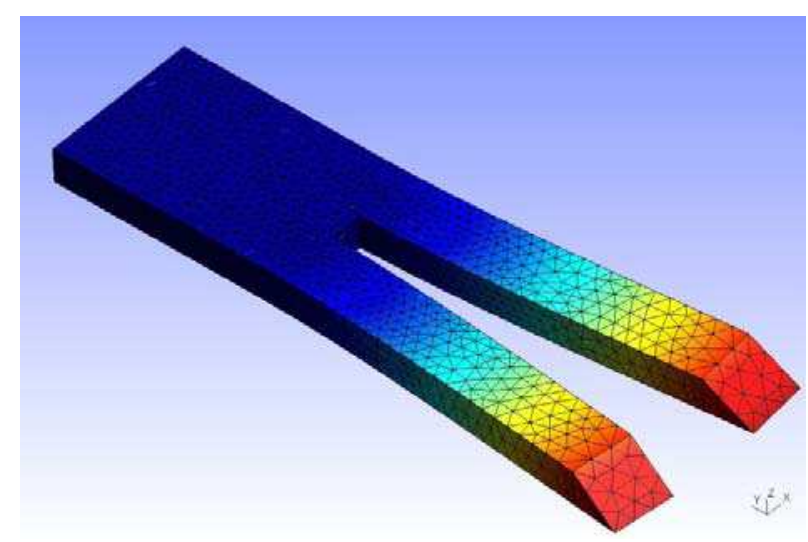

FIG. 5. Calculated displacement field of the QTF in its first symmetric vibration mode @ $32 \mathrm{kHz}$ (Freefem,++ Gmsh)
FIG. 4 Piezoelectric response of the QTF. Image of the QTF electrodes (a), mapping of the piezoelectric signal modulus from a complete scan of the QTF with linear (b) or non linear color scale (c).

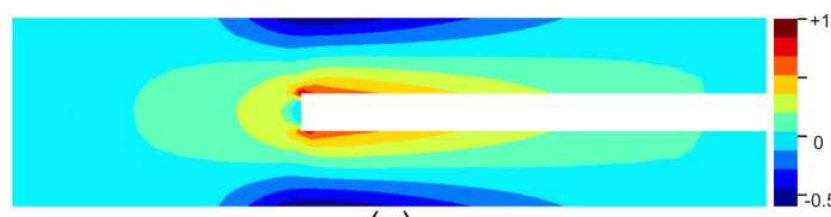

(a)

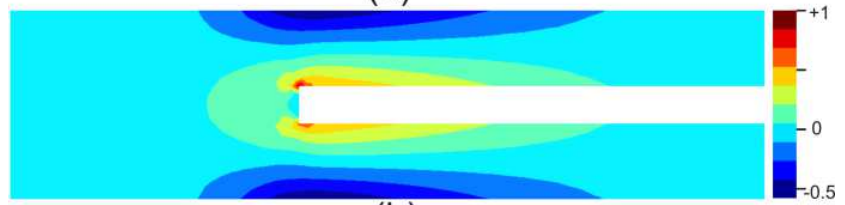

(b)

FIG. 6. Modeling of the QTF in its first symmetric vibration mode at $32 \mathrm{kHz}$ (FreeFem++, Gmsh): strain $\varepsilon_{y y}$ (a) and stress $T_{y y}$ (b), both in normalized linear color scale.

Numerical results have been obtained using quadratic elements. Figure 5 shows the displacement field for the first symmetric vibration mode at $32 \mathrm{kHz}$ and the mesh which consists of about 20000 tetrahedras. Figs. $6 \mathrm{a}$ and $6 \mathrm{~b}$ gives the related calculated strain and stress mapping of the QTF. Only the y-components, which are dominant, are represented. These simulations are in good agreement with the experimental mapping of the sensitivity: we can identify the highest strain areas which are near the basis of the prongs and the line of null strain in the middle of each prong.

To demonstrate the capability of our detection scheme we used a grid of carbon black, which absorbs in the infrared domain, deposited on a metallic surface, and a non 
encapsulated QTF. The setup is depicted on Figure 7: the source is a stabilized $\mathrm{CO}_{2}$ laser with a $\mathrm{TEM}_{00}$ mode and a power of $1 \mathrm{~W}$ at the wavelength of $10.6 \mu \mathrm{m}$. The beam power is modulated by an acousto-optic modulator. Various $\mathrm{ZnSe}$ optics allow the beam expansion and a fine focusing on the sample and on the QTF (Figure 7a). Figure 8 shows the variations of the piezoelectric signal of the QTF in the far field configuration while the laser spot scans the grid. In spite of the noise due to the speckle present in the diffused light, the signal minima are consistent with the presence of carbon black. The contrast of the signal is $69 \%$; a contrast of $80 \%$ was obtained with a thicker layer. This confirms that this method can be used to detect pollutants. With a simplified non-imaging setup (Figure $7 \mathrm{~b}$ ) where the sample is positioned a few millimeters behind the QTF and the laser beam focused between the QTF prongs, analog results are obtained. However the contrast varies irregularly with the proximity between the QTF and the surface at very short distances $(<0.5 \mathrm{~mm})$. Complementary studies are necessary to confirm if these kind of "near-field" conditions are favorable to a real detection of the acoustic wave generated by the heated surface.

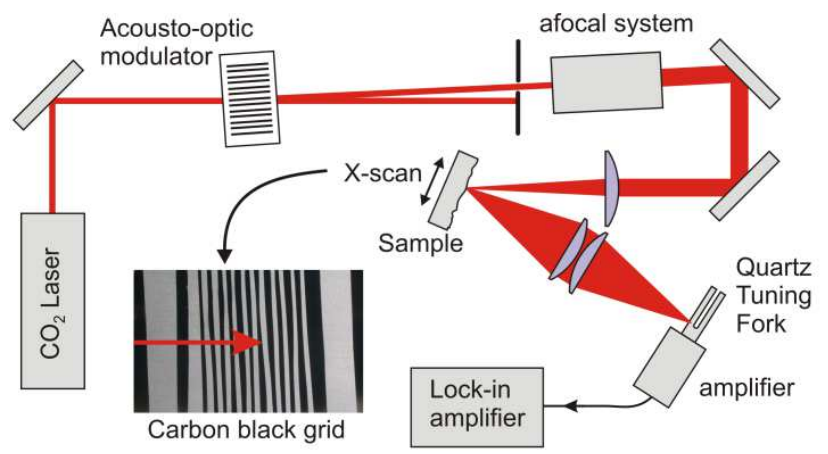

(a)

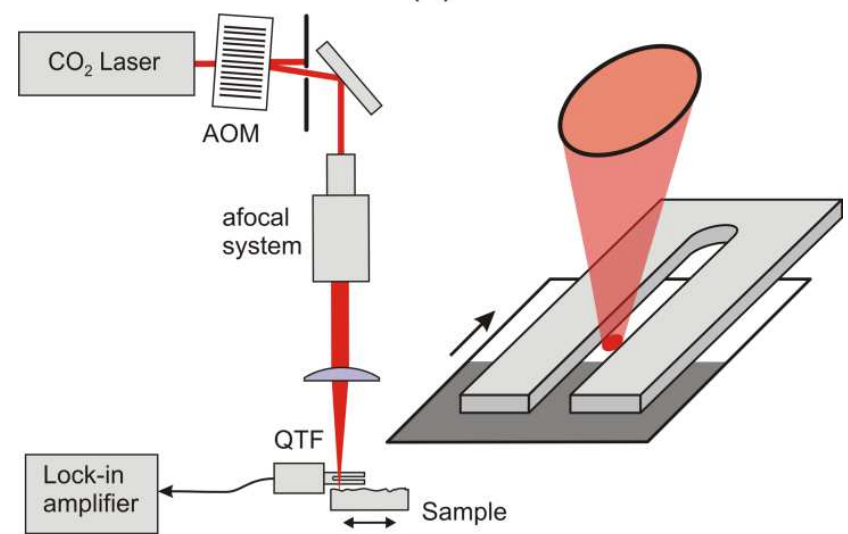

(b)

FIG. 7. Set-up of the absorption measurement in the reflection configuration: imaging (a), non-imaging (b).

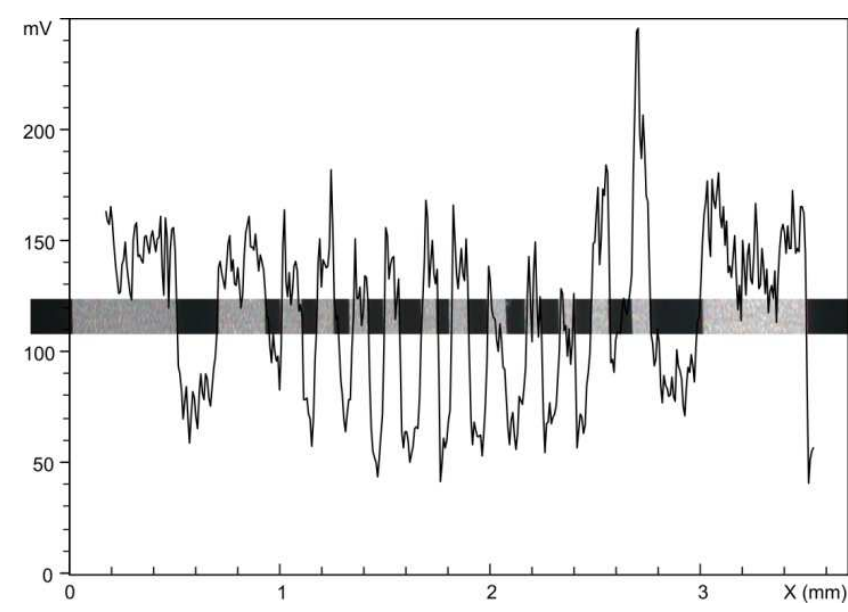

FIG. 8. Variation of the piezoelectric signal during a single scan of the carbon black grid.

As a conclusion, detecting a larger signal with encapsulated QTF and the similarity between sensitivity and stress/strain mapping allow us to consider the photothermoelastic excitation as being the main origin of the mechanical vibration. Focusing in the high strain region of the vibration mode ensures the best coupling between the photo-thermal excitation and the mechanical vibration. Further simulations will take into account the full coupling thermoelastic interactions to study the influence of the laser impact position, the influence of metal electrodes, and thus find the optimal excitation point or the optimal resonator geometry. Finally the full coupling thermo-piezoelectric interactions will enable to describe the electrical behavior.

This work has been carried out within GENESIS project, funded by OSEO Innovation. The authors would like to thank FreeFEM, the free differential equation solver that was used for simulations.

\footnotetext{
${ }^{1} 1$ H. Edwards, L. Taylor, W. Duncan, A.J. Melmed, J. Appl. Phys. 82, 980 (1997).

${ }^{2}$ F J. Giessibl, Appl. Phys. Lett. 73, 3956 (1998).

${ }^{3}$ Yexian Qin, R. Reifenberger, Rev. Sci. Instrum. 78, 063704 (2007).

${ }^{4}$ M. Todorovic and S. Schultz, Appl. Phys. Lett. 73, 3595 (1998).

${ }^{5}$ R.D. Grober, J. Asimovic, J. Schuck, D. Hessman, P.J. Kindlemann, J. Hespanha, S. Morse, K. Karrai, I. Tiemann, S. Manus, Rev. Sci. Instrum. 71, $2776(2000)$

${ }^{6}$ K. Karrai, R. D. Grober, Ultramicroscopy 61, 197 (1995).

${ }^{7}$ N. Petra, J. Zweck, A.A. Kosterev, S.E. Minkoff, D. Thomazy, Appl. Phys. B 94, 673 (2009).

${ }^{8}$ C. W. Van Neste, L. R. Senesac, T. Thundat, Appl. Phys. Lett. 92, 234102 (2008).

${ }^{9}$ Y. Song, B. Cretin, D. M. Todorović, P. Vairac, J. Appl. Physics 104, 104909 (2008).

${ }^{10}$ J. R. Barnes, R.J. Stephenson, C. N. Woodburn, S.J. O’Shea, M. E. Welland, T. Rayment, J.K. Gimzewski, Ch. Gerber, Rev. Sci. Instrum. 65, 3793 (1994). Erratum: Rev. Sci. Instrum. 66, 3083 (1995).

${ }^{11}$ G. R. Buchanan, J. Sound Vib. 294, 362-367 (2006).

${ }^{12}$ R.D. Mindlin, Int. J. Solids Struct. 10 (6), 625-637 (1974).

${ }^{13}$ W. Nowacki, J. Therm. Stresses 1 (2), 171-182 (1978).

${ }^{14}$ See supplementary material in $\mathrm{F}$. Hecht, Freefem ++ manual, version 3.20 (2012), URL http://www.freefem.org/ff $++/$ ftp/freefem++doc.pdf

${ }^{15} \mathrm{C}$. Geuzaine, J-F Remacle, Int. J. Numer. Methods Eng. 79, 1309 (2009).
} 